\title{
Title: Rigid Molecular Foams
}

Author(s):

Submitted to:

W. P. Steckle, Jr., MST-7

M. A. Mitchell, Chemdal Corp.

P. G. Apen, Simula Inc.

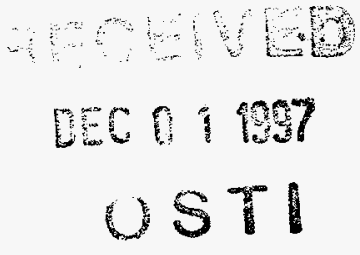

OSTI

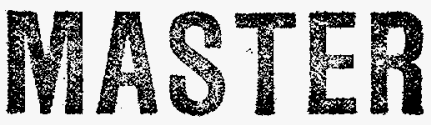

DGTRIBUTION OF THS DOCURENT IS UEMTET

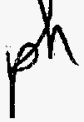

\section{Los Alamos}

NATIONAL LABORATORY

Los Alamos Natlonal Laboratory, an affirmative action/equal opportunity employer, is operated by the University of Califomia for the U.S. Department of Energy under contract W-7405-ENG-36. By acceptance of this article, the publisher recognizes that the U.S. Government retains a nonexclusive, royaltyfree license to publish or reproduce the published form of this contribution, or to allow others to do so, for U.S. Government purposes. Los Alamos National Laboratory requests that the publisher identify this article as work performed under the auspices of the U.S. Department of Energy. Los Alarnos National Laboratory strongly supports academic freedom and a researcher's right to publish; as an institution, however, the Laboratory does not endorse the viewpoint of a publicalion or guarantee its technical correctness. 


\section{DISCLAIMER}

This report was prepared as an account of work sponsored by an agency of the United States Government. Neither the United States Government nor any agency thereof, nor any of their empioyees, makes any warranty, express or implied, or assumes any legal liability or responsibility for the accuracy, completeness, or usefulness of any information, apparatus, product, or process disclosed, or represents that its use would not infringe privately owned rights. Reference herein to any specific commercial product, process, or service by trade name, trademark, manufacturer, or otherwise does not necessarily constitute or imply its endorsement, recommendation, or favoring by the United States Government or any agency thereof. The views and opinions of authors expressed herein do not necessarily state or reflect those of the United States Government or any agency thereof. 


\section{DISCLAmisx}

Portions of this doenment may be illegible in electronic image produets. Images are produced from the best available original documente 


\title{
Rigid Molecular Foams
}

\author{
Warren P. Steckle, Jr. ${ }^{*}$ \\ Materials Science and Technology Division, Los Alamos National Laboratory \\ Michael A. Mitchell \\ Chemdal Corporation, 1530 E. Dundee Rd., Suite 350, Palatine, IL 60067 \\ Paul G. Apen \\ Simula Inc., 10016 S. 51st St., Phoenix, AZ 85044
}

\begin{abstract}
This is the final report of a three-year, Laboratory Directed Research and Development (LDRD) project at the Los Alamos National Laboratory (LANL). Organic analogues to inorganic zeolites would be a significant step forward in engineered porous materials and would provide advantages in range, selectivity, tailorability, and processing. Rigid molecular foams or "organic zeolites" would not be crystalline materials and could be tailored over a broader range of pore sizes and volumes. A novel process for preparing hypercrosslinked polymeric foams has been developed via a Friedel-Crafts polycondensation reaction. A series of rigid hypercrosslinked foams have been prepared using simple rigid polyaromatic hydrocarbons including benzene, biphenyl, m-terphenyl, diphenylmethane, and polystyrene, with dichloroxylene (DCX) as the crosslinking agent. Transparent gels are formed suggesting a very small pore size. After drying the foams are robust and rigid. Densities of the resulting foams can range from $0.15 \mathrm{~g} / \mathrm{cc}$ to $0.75 \mathrm{~g} / \mathrm{cc}$. Nitrogen adsorption studies have shown that by judiciously selecting monomers and the crosslinking agent along with the level of crosslinking and the cure time of the resulting gel, the pore size, pore size distribution, and the total surface area of the foam can be tailored. Surface areas range from 160 to $1,200 \mathrm{~m}^{2} / \mathrm{g}$ with pore sizes ranging from $6 \AA$ to $2,000 \AA$.
\end{abstract}

\section{Background}

Porous materials are widely used in government and industry for chemical separations, processing and monitoring, environmental cleanup and remediation, energy efficiency, and conservation. Porous materials used in these applications include foams, filters, membranes, absorbents, ion exchange resins, molecular sieves, zeolites, catalyst supports, sensors, and electrodes.

All materials can be made porous. Polymers, for example, can be processed into foams using blowing agents, by phase separations from solvent, or by extraction of pore formers. Synthetic polymeric foams are most widely used in thermal insulation,

\footnotetext{
•Principal investigator, E-mail: steckle@lanl.gov
} 
packaging, lightweight materials, and buoyant structures. The microscopic structure and composition of the porous polymer directly affect the properties and characteristics of the bulk foam. Porosity is generally controlled at the microscopic level using appropriate fabrication and processing techniques. Polymeric foams have found limited use in many of the applications described above because it is currently impossible to control foam morphology at the sub-micron level using conventional foam producing techniques. Direct, predictable manipulation of the pore size, pore distribution, and pore chemistry at the nanometer level will produce the next generation of porous materials useful for chemical separations and processing. Control at this level is critical for precisely tailoring the physical and chemical interactions, reactions, and properties of the bulk porous material. Significant benefits are expected in the areas of energy and process efficiency, waste remediation and minimization, and conservation if such control is achieved.

There are numerous efforts in the materials science community directed towards producing well-defined materials that are engineered at the sub-micron level. Hyperbranched and hypercrosslinked polymers are two prominent examples. Polymer scientists are now able to manipulate polymers at the nanometer level by producing hyperbranched monodisperse entities with well-defined sizes, structures, and functionalities [1-4]. Hyperbranched polymers are truly intriguing from a theoretical standpoint. However, they have found no practical applications besides their limited roles as molecular sizing standards and viscosity modifiers. Preparation of hyperbranched structures often requires expensive starting materials, numerous synthetic steps, and rigorous purification procedures to obtain just a few milligrams of product. Hypercrosslinked polymers are also receiving attention because polymer scientists are attempting to control porosity in rigid-rod polymers and organic-inorganic hybrids at the nanometer level using low temperature condensation reactions [5] or sol-gel processing [6] techniques. While some successes are noted, the starting materials can be expensive or difficult to synthesize. In addition, the crosslinking reactions are cumbersome and not amenable to large scale preparations.

Although promising, these novel hyperbranched and hypercrosslinked polymers are still unable to compete with commercially available macroporous materials including lightly crosslinked polystyrene resins which are commonly used in separations, chromatography, and ion exchange. Surprisingly, hypercrosslinked forms of polystyrene are relatively unknown and are not commonly used for separations. However, there are several reports describing truly phenomenal properties in hypercrosslinked polystyrenes which suggest that these materials may be superior to traditional polystyrene resins [7- 
11]. Hypercrosslinked polystyrenes have extraordinarily high surface areas, swell in thermodynamically unfavorable solvents, absorb dyes and hydrocarbons, and readily absorb gases. These phenomena, which are not observed in linear or lightly crosslinked polystyrene resins and beads, are attributed to the high frequency of rigid crosslinks which do not allow the polymeric network to collapse. This leaves a true nanoporous material with extraordinarily high surface areas and exceptional absorptive capacity. Despite these wonderful properties, several drawbacks are apparent. The nanostructure cannot easily be varied since the pore sizes and volumes are determined solely by the length and structure of the crosslinking agent. The flexible backbone of the polystyrene starting material requires that rigid crosslinkers be employed in order to obtain true nanoporosity in the bulk material [12]. Since only a handful of rigid crosslinking agents is readily available, flexibility of design is reduced and a broad spectrum of properties are never realized. Hypercrosslinked polystyrenes, like the linear and lightly crosslinked versions, possess a low glass transition temperature and a low decomposition temperature [13]. These undesirable characteristics prevent their use in harsh environments.

\section{Research Objective}

The objective of this work is to demonstrate and develop rigid molecular foams as useful media for conducting chemical separations. This requires evaluating this new type of foam as absorbent, filter, zeolite, and chromatographic material.

It is critical that the surface areas, pore sizes, pore volumes, and cell sizes be varied systematically and that these factors be correlated to initial processing conditions-including the nature and concentration of the polyaromatic hydrocarbons (PAH) and rigid aromatic crosslinking agents $(\mathrm{XL})$, the reaction conditions, the polymerization catalyst, and the degree of crosslinking. Thus, an important part of this work is the correlation of foam properties with nanostructure.

Initial goals will focus on the separation of volatile organic compounds (VOCs) from inert gas streams and from nonvolatile solvents and components. This is of prime interest to the Department of Energy (DOE) where VOC contamination of the soil and groundwater within the DOE complex poses a significant problem. 


\section{Scientific and Technical Impact}

The development of new porous materials is essential as industry and government continue to be faced with mounting challenges in energy conservation, environmental remediation, source reduction, and process efficiency. Nanometer scale engineering holds tremendous potential for solving these difficult problems and will define the next generation of porous materials.

Nanoporous rigid molecular foams will have significant scientific and technical impact in the field of engineered porous materials. Novel nanostructures and unique nanonetworks can be realized from this project, simply by using adaptations of a known polycondensation reaction. Pore sizes can be varied from five to fifty angstroms and beyond. Systematic control on this scale will produce materials with astounding surface areas critical for gas and small molecule separations. With extraordinarily small pore sizes, these materials will be ideal media for separating a range of organic solutes from solutions by filtration. Rigid molecular foams could really be viewed as "molecular filters". Separations would be based primarily on molecular size and weight. High separation factors could be achieved for both low and high molecular weight organics based solely on the pore size of the molecular foam.

The enormously high surface areas that are achievable in rigid molecular foams indicate that they should not only act as filters, but actually absorb several times their weight of "solute" from solutions. Currently, only inorganic nanoporous materials, such as aluminosilicate zeolites, can absorb molecules of narrow molecular weight range. Organic analogues to inorganic zeolites would be a significant step forward in engineered porous materials and would provide advantages in range, selectivity, tailorability, and processing. Rigid molecular foams or "organic zeolites" would not be crystalline materials and, as a result, could be tailored over a broader range of pore sizes and volumes. By varying pore volume and cell size, organic materials from low to high molecular weight, and over a narrow weight range, could be absorbed from solution into the pores of the foam. This has implications for hydrocarbon cracking and processing, polymer processing, drug purification, and biotechnology where proteins and enzymes are prepared and separations are laborious.

Versatility is a cornerstone of the rigid molecular foam concept. Compared to existing methods for producing hypercrosslinked materials, Friedel-Crafts polycondensation offers control over both the monomer and crosslinker size, structure, and chemistry. As a consequence, this process is adaptable to more complex systems. For example, functionalization of the polyaromatic hydrocarbons or the rigid aromatic 
crosslinking agents prior to and after polymerization is possible. The pore interiors could be functionalized with charged or hydrophilic species. Functionalized rigid molecular foams would perhaps even be effective for separations of metal ions from aqueous streams.

Carbon and graphitic materials play a major role in chemical purification, absorption, and catalysis. Activated carbon powders, in particular, find many uses in chemi- and physi-sorption of impurities. High surface area carbons are also used as catalytic substrates for numerous chemical reactions. Hypercrosslinked poly(arylene methylenes) are potentially valuable carbon precursors. Carbonization of nanoporous poly(arylene methylenes) is expected to give nanoporous carbons or graphite with large surface areas suitable for separations.

In conclusion, new engineered porous materials will continue to be of interest in applications important to short and long term industrial competitiveness. Consequently, both cooperative research and development agreements and technology transfer initiatives could result from this project. Potential industrial collaborators include Rohm and Haas, Amoco, Dow Chemical, DuPont, American Cyanamid, and Union Carbide. Biotechnology and pharmaceutical companies may also be interested in these materials for separations science.

\section{Scientific Approach}

Robust, easily tailorable, nanoporous, rigid, hypercrosslinked polymeric materials do not exist. We investigated a simple, one-step process from inexpensive raw materials to nanoporous hypercrosslinked polymers. Polycondensation of rigid PAH using XL will provide a simple, yet versatile, method for preparing rigid hypercrosslinked poly(arylene methylenes).

This straightforward polycondensation, known as Friedel-Crafts polycondensation, has been applied to similar aromatic systems in an attempt to obtain linear poly(arylene methylenes) [14-25]. In this early work, researchers were unable to prevent crosslinking and typically recovered insoluble, infusible polymers [14-16]. Although the majority of these materials were poorly characterized, there is cursory literature evidence that crosslinked poly(arylene methylenes) possess properties desirable for separation media. Even the lightly crosslinked polymers swell upon standing in various solvents $[17,19]$, uptake a variety of substances from solution $[22,24]$, and possess high thermal stabilities [19-21, 25]. 
It would be a simple matter to drive the polycondensation reaction to completion using an excess of XL thereby creating a rigid hypercrosslinked polymer. A variety of rigid PAH monomers and XLs, differing in size and structure, are readily available. For example, aromatic hydrocarbon monomers such as 1,3,5-triphenylbenzene, $p$-terphenyl, biphenyl, and diphenylmethane, and crosslinking agents such as $p$-dichloroxylene and $m$ dichloroxylene, are inexpensive starting materials which will undergo Friedel-Crafts polycondensation. The porous structures obtained from this process are true molecular "foams" containing nanometer sized cells defined by the rigid aromatic linkages which form the "cell struts" and "faces". They can accurately be described as rigid molecular foams. By judicious choice of monomer and crosslinking agent, the surface area, cell size, pore size and volume, degree of crosslinking, and bulk properties will be varied separately and simultaneously. Figures 1 and 2 below illustrate in two dimensions how the cell and pore size can be substantially altered by simply using different PAH monomers (aromatic rings are depicted as simple hexagons). The PAH in Figure 1 is 1,3,5-triphenylbenzene, while in Figure 2 it is diphenylmethane. In both cases, the XL is xylylene dichloride and the ratio of crosslinker to monomer (PAH to $\mathrm{XL}$ ) is two to one.

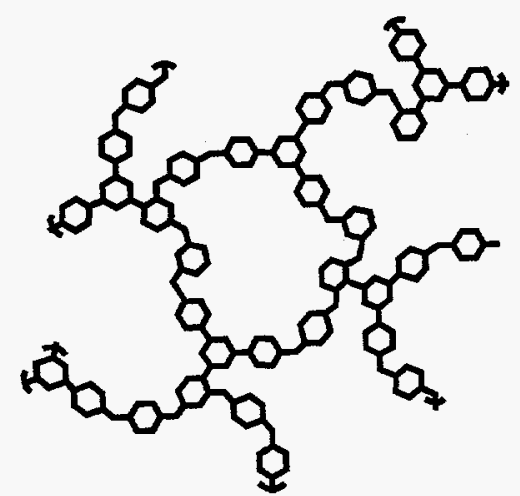

Figure 1. PAH monomer for $1,3,5-$ triphenylbenzene.

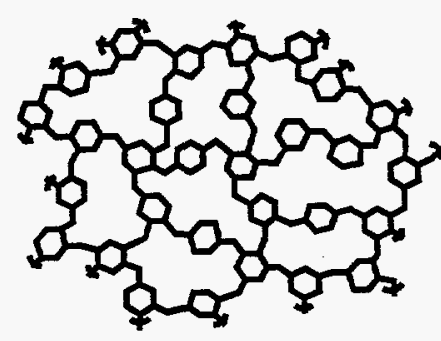

Figure 2. PAH monomer for diphenylmethane.

Rigid molecular foams have ideal nanostructures for use as absorbents and chromatographic media, molecular filters and sieves, catalysts, catalyst supports, and organic zeolites. This new class of materials will be thoroughly evaluated as media for chemical separations and processing. In addition, due to their high carbon and low 
hydrogen contents, hypercrosslinked poly(arylene methylenes) will be evaluated as precursors to nanoporous carbon/graphite.

\section{Experimental}

Materials. All of the polyaromatic hydrocarbons, crosslinking agents, catalyst, and solvents were purchased from Aldrich, except for the three polystyrene precursors which were purchased from Polysciences. Air Products supplied the carbon dioxide. Unlike previous synthesis, all the reactants, solvents, and catalyst were used as supplied.

Samples were typically prepared by first dissolving the PAH and $\mathrm{XL}$ in dichloroethane. The concentrations of PAH and XL were varied from $0.10 \mathrm{~g} / \mathrm{cc}$ to 0.20 $\mathrm{g} / \mathrm{cc}$ in the precursor solution. Tin tetrachloride, used as the Friedel-Crafts catalyst, was added at this point. This solution was allowed to react for $1-24$ hours at $60^{\circ} \mathrm{C}$. Once the gel had cured, any catalyst and unreacted monomers were extracted from the gel using a solvent such as acetone or methanol. Elemental analysis has shown that the removal of catalyst is quantitative under the conditions used. The solvent was removed from the gel via supercritical extraction with carbon dioxide.

Analytical Methods. Surface area analysis was done using a Micromeritics ASAP 2010 Surface Area Analyzer. Nitrogen adsorption measurements were performed at $77 \mathrm{~K}$. Surface areas were calculated according to theory as developed by Brunauer, Emmett, and Teller (BET) [26]. Micropore volume and surface area distributions were calculated according to Horvath-Kawazoe (H-K) theory [27]. The Barrett, Joyner, and Halenda $(\mathrm{BJH})$ [28] method was used in determining the pore volume and surface area distributions for the mesopores. More recently, Density Functional Theory (DFT) [29] has become a powerful tool in the area of pore size analysis. This provides a profile of both surface area and pore volume from $2 \AA$ up to $4,000 \AA$ in a single analysis, unlike any of the aforementioned techniques.

Nuclear magnetic resonance (NMR) spectra were obtained on a Bruker ASX-300 solid state NMR spectrometer. Data was collected using either high power decoupling (HPDEC) or cross polarization magic angle spinning (CP-MAS) experiments. The experiments were generally carried out with a $1 \mathrm{msec}$ contact time and a delay of $5 \mathrm{sec}$ for the CP-MAS experiments and $10 \mathrm{sec}$ for the HPDEC experiments. The $90^{\circ}$ pulse lengths were $8 \mu \mathrm{sec}$ for CP-MAS experiments and $12 \mu \mathrm{sec}$ for the HPDEC experiments. Spin rates of $10 \mathrm{kHz}$ were used to remove spinning sidebands from the region of interest.

Thermogravimetric analysis (TGA) was performed using a Polymer Laboratories TGA in air and nitrogen atmospheres with a flow rate of $10 \mathrm{ml} / \mathrm{min}$ and with a heating rate of $10^{\circ} \mathrm{C} / \mathrm{min}$. Micrographs were obtained using a Jeol transmission electron 
microscope (TEM). Nonpyrolyzed samples were stained with ruthenium tetraoxide in order to improve contrast.

\section{Accomplishments}

A wide range of pore size distributions and surface areas are possible for this class of hypercrosslinked materials. Table I shows the wide range of total surface area (SA) attainable by the choice of appropriate monomer and crosslink ratio. The greatest influence on the total surface area comes from the choice of monomer. Surface areas as low as $160 \mathrm{~m}^{2} / \mathrm{g}$ can be achieved by using bibenzyl hypercrosslinked with dichloroxylene at a ratio of 1:1.5. Molecular modeling has shown that the simple aromatic monomers yield a crosslinked structure which is more open than the higher surface area foams such as polystyrene. The overall average pore size in both the micropore range and mesopore range is seen to decrease as the surface area increases. Both the $\mathrm{H}-\mathrm{K}$ and $\mathrm{BJH}$ mean pore sizes tend to decrease in Table $I$ as the surface area increases. It would follow that additional crosslinks in the network would reduce the number of larger pores in the foam and there would be a corresponding increase in the number of smaller pores. The real effect on the pore size distribution is more clearly illustrated in Figure 3. As the network becomes denser, the distribution shifts from pores in the hundreds of angstroms to those in the tens of angstroms, and even as low as $5 \AA$.

Table I. Surface Area Analysis Results for Different Monomers and Crosslink Ratios

\begin{tabular}{|l|l|l|l|l|}
\hline Monomer & XL Density & BET SA & H-K pore & BJH pore \\
\hline & & $\left(\mathrm{m}^{2} / \mathrm{g}\right)$ & $(\mathrm{A})$ & $(\mathrm{A})$ \\
\hline Bibenzyl & 1.50 & 159.9 & 7.1 & 215.5 \\
\hline Biphenyl & 1.50 & 291.5 & 6.7 & 211.8 \\
\hline Diphenylmethane & 1.50 & 291.9 & 9.9 & 259.9 \\
\hline Triphenylbenzene & 1.50 & 311.4 & 6.6 & 122.6 \\
\hline Diphenylmethane & 2.00 & 370.2 & 6.6 & 144.6 \\
\hline Biphenyl & 1.75 & 470.6 & 7.4 & 153.9 \\
\hline Biphenyl & 2.00 & 603.3 & 7.2 & 125.0 \\
\hline Triphenylbenzene & 2.00 & 636.2 & 6.8 & 112.4 \\
\hline Benzene & 1.50 & 692.1 & 6.2 & 155.7 \\
\hline PS-50k & 1.50 & 994.8 & 6.2 & 128.6 \\
\hline PS-280k & 2.00 & 1096.0 & 6.3 & 148.3 \\
\hline PS-50k & 2.00 & 1204.4 & 6.0 & 105.8 \\
\hline
\end{tabular}




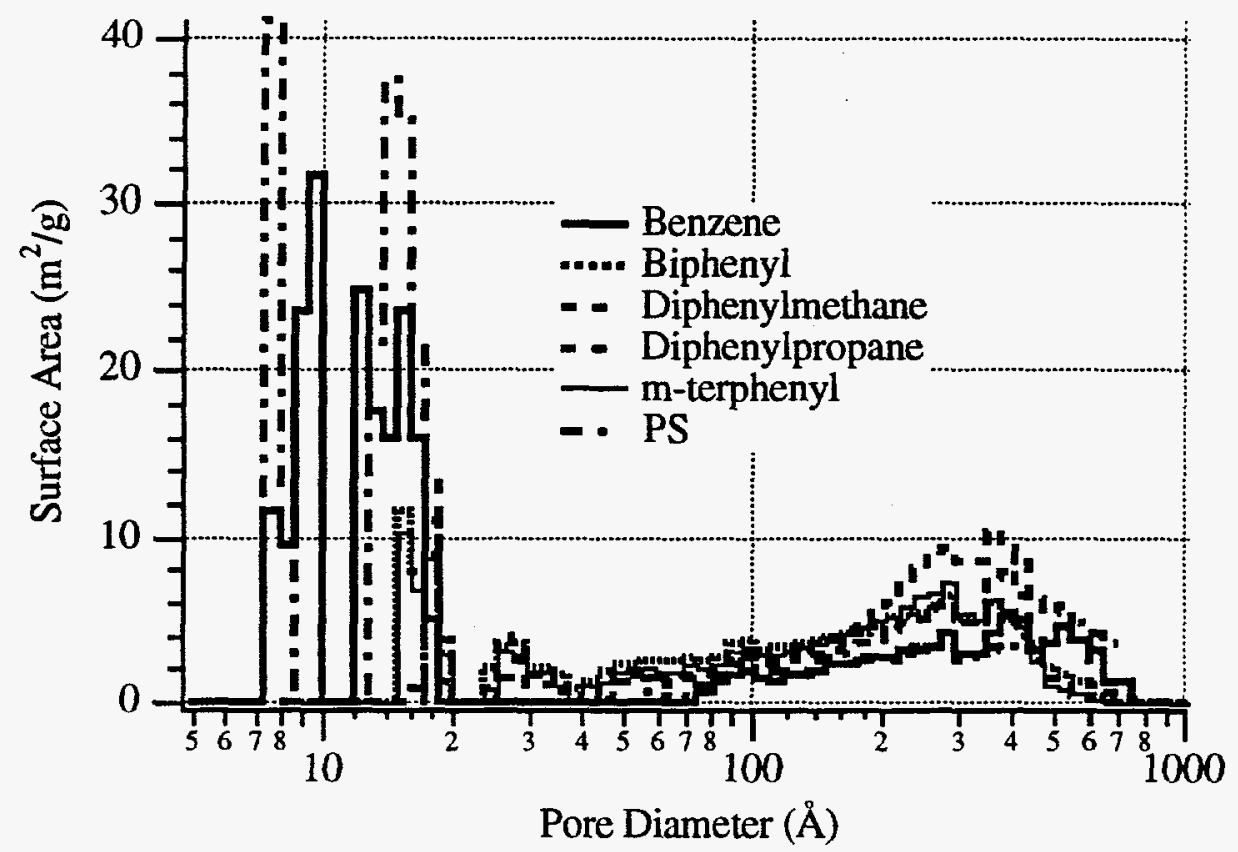

Figure 3. DFT pore size distribution for different monomers hypercrosslinked with dichloroxylene at 1:2 molar ratio.

Although these surface area distributions tend to emphasize the smaller pores, a similar decrease in the larger pores can be seen in pore size distributions in terms of pore volume. Distributions determined via the $\mathrm{H}-\mathrm{K}$ or $\mathrm{BJH}$ methods do not cover a range as great as that encompassed by the DFT method. Surface area distributions tend to emphasize the smaller pores, whereas the pore volume distributions tend to emphasize the larger pores. Only the surface area distributions are reported here.

A doubling in the surface area is seen as the crosslink ratio for biphenyl is increased from 1:1.5 to 1:2. The average size of the mesopores is seen to decrease from $212 \AA$ to $125 \AA$, yet the average micropore size is seen to increase. The dramatic increase in surface area for hypercrosslinked polystyrene appears to occur as the crosslink ratio is increased from 1:0.5 to 1:1. Although Figure 3 shows an increase in the amount of fine structure in the resulting foam, it seems that there is a balance between the surface area attributed to the bimodal distribution of micropores and mesopores. Although not shown here, much of the resulting pore volume of even the highly crosslinked foams arises from pores several hundred angstroms in size. These larger pores help facilitate transport through the foam, where the smaller pores effect the separation ability of the foams. 
It is impossible to achieve full crosslinking in the sample that has three times the molar ratio of dichloroxylene since there clearly are not enough reactive sites on the aromatic ring of the polystyrene. Steric considerations and decreasing chain mobility also clearly prevent complete crosslinking at high concentrations of crosslinking agent. Although dichloroxylene can react with itself under harsh conditions, these conditions were not approached during the preparation of the samples in this study. Infrared evidence from work in our laboratories indicates a high degree of tri-substituted and possibly tetra-substituted aromatics.

Crosslink density is also affected by the amount of time given for the system to react. In this case the time reported is from the onset of gelation. Samples were quenched with acetone and worked up in the standard manner. Surface area increases as the reaction time in the gel state increases. This increase in surface area can be attributed to the formation of more smaller pores. As one would expect, once gelation occurs there is a loss of mobility in the system. This is seen by a greater shift in the pore size distribution for the shorter times and only a minimal change between the 4 hour curve and 24 hour curve. The pore size distribution in terms of pore volume for this system shows that the number of pores on the order of $1,000 \AA$ decreases as a function time.

Two different trends in thermal stability are exhibited in the thermogravimetric analysis of a series of hypercrosslinked polystyrene (PS) foams crosslinked with increasing levels of dichloroxylene (DCX). In nitrogen, an overall increase in stability is observed (see Figure 4). Similar to the surface area behavior, the greatest increase in stability is observed as the crosslink ratio is increased to a ratio of 1:1.5. This is to be expected since a greater number of crosslinks in the material would inhibit its degradation. After this, only a modest gain in stability is observed with crosslink ratios greater than 1:1.5. In air, the trend is just the opposite. Samples with greater surface area would be more accessible to oxidation; therefore, the samples with the lower crosslink density would have greater stability in air. 


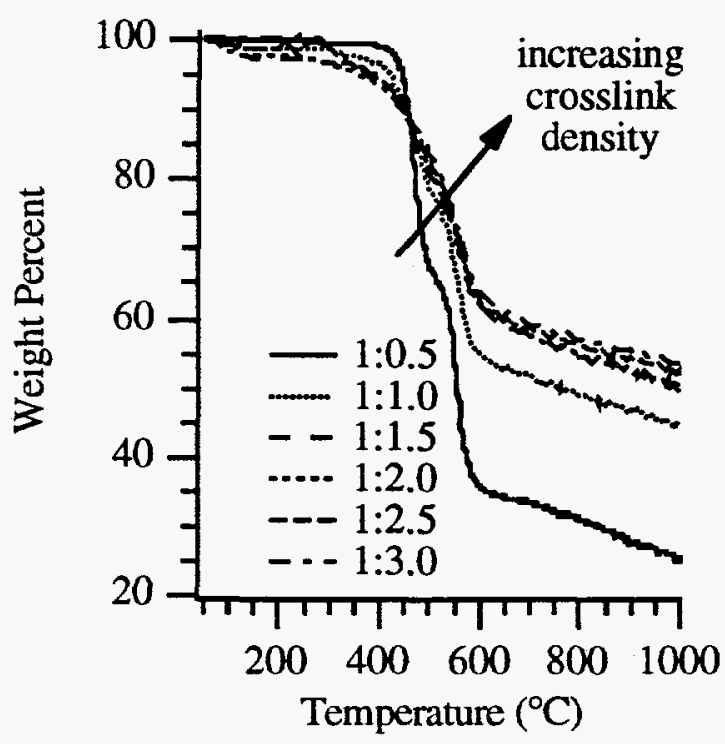

Figure 4. Thermal stability in nitrogen for a series of hypercrosslinked polystyrene foams crosslinked with DCX.

Preparation of Carbon Foams from Hypercrosslinked Foams. Pyrolysis of these polymeric foams was done in a Lindberg single zone quartz tube furnace equipped with a temperature profile controller. Heating rates ranged from $1{ }^{\circ} \mathrm{C} / \mathrm{min}$. to $10^{\circ} \mathrm{C} / \mathrm{min}$. to temperatures as high as $1,000^{\circ} \mathrm{C}$. Soak times of 8 hours were generally used to allow for uniformity throughout the sample. Samples were cooled down to room temperature before removal from the furnace. Ports on the furnace readily allowed for different pyrolysis atmospheres. Samples were suspended in the furnace on a platinum hang-down to a point where the thermocouple was located.

The following sample designation was used: carXXYYY/ZZZ, where car denotes that the sample was pyrolyzed, XX denotes the precursor foam, YYY is the initial pyrolysis temperature, and $\mathrm{ZZZ}$ is the second pyrolysis temperature when two-step pyrolysis was employed. Although many different hypercrosslinked samples have been previously prepared, the following XX were chosen for this study: benz = benzene, $\mathrm{BP}=$ biphenyl, TP = m-terphenyl, and PS = polystyrene. A crosslinking ratio of 1:2(PAH/XL) was chosen.

Pyrolysis temperature was varied from sample to sample. Initial attempts at pyrolysis were done at $500^{\circ} \mathrm{C}$ for all samples under vacuum. It appears that the optimum temperature for pyrolysis is related to the temperature at which the initial weight loss occurs in the TGA. The closer the temperature is to this point, the more the precursor volatilizes, leaving large voids in the foam. When the temperature is kept $25^{\circ} \mathrm{C}$ below this initial weight loss temperature, there is uniform pyrolysis throughout the sample with 
a maximum retention of porosity. Much below this temperature there is an incomplete pyrolysis of the sample, even at longer soak times up to 24 hours. Incomplete pyrolysis was confirmed by both Fourier Transform Infrared (FTIR) analysis and NMR studies.

The atmosphere under which the pyrolysis was conducted was found to have a profound effect upon the properties of the resulting foam. The BET surface areas are at least an order of magnitude lower for all those samples that were pyrolyzed in either vacuum or nitrogen than for those pyrolyzed in static air. Those that were heated in flowing air were reduced to ash. Degradation of crosslinked styrene/divinylbenzene (DVB) leads to the formation of volatile by-products that are mainly styrene, but hydrogen, methane, ethylene, benzene, and toluene are also produced. As the samples are heated under a dynamic atmosphere, the volatile compounds that result from degradation are then swept away from the foam, whereas the volatiles that come off in a static atmosphere have the opportunity to redeposit themselves back onto the surface of the foam. Although there is a significant loss of surface area and porosity as the sample loses weight, the overall pore size distribution is retained. Although the surface area for a given pore size is nearly two orders of magnitude lower for the vacuum pyrolyzed sample, the pore size distribution is comparable between $15 \AA$ and $1,500 \AA$.

Two Stage Pyrolysis. Preparation of graphitic carbon foams was also of interest. In order to achieve graphitization, samples needed to be heated to temperatures in excess of $1,200^{\circ} \mathrm{C}$. Although the temperature for graphitization could not be achieved in the furnace being used, it was of interest to investigate the dehydrogenation process of these materials. As mentioned earlier, samples that were heated to too high an initial temperature tended to form foams with very large pores. At these high initial temperatures the foam degrades at a rate such that the degradation products volatilize rapidly enough to form these large pores at the expense of the initial architecture.

In an effort to pyrolyze these materials at higher temperatures, the hypercrosslinked precursor was first heated to a lower temperature where an optimum retention of pores was found. This generally involved pyrolyzing the foam in static air before subsequent high temperature pyrolysis. The use of multiple step temperature ramps is common in the preparation of a carbogenic molecular sieve (CMS) from polyfurfurly alcohol (PFA) or polyvinylidene chloride (PVDC) to provide an optimum porosity. Similarly an oxidative, low temperature step is utilized to not only increase the porosity of the foam, but also to reduce shrinkage.

A series of carbenz foams was prepared, starting with carbenz500 pyrolyzed in static air. Benzene/DCX was initially chosen for high temperature pyrolysis due to its high char yield as exhibited by TGA. Carbenz500 retains over seventy percent of its 
porosity during the first pyrolysis step. As the temperature of the second pyrolysis stage is increased from $600^{\circ} \mathrm{C}$ to $1,000^{\circ} \mathrm{C}$ there is a gradual decrease in surface area from 484 $\mathrm{m}^{2} / \mathrm{g}$ to $208 \mathrm{~m}^{2} / \mathrm{g}$. Char yield for these foams is high and weight loss alone does not account for the change in porosity. The DFT pore size distribution as a function of surface area shows a gradual decrease in the surface area for a given pore size with only a slight shift in overall distribution. Upon pyrolysis the size of the pores increases, which is in agreement with nitrogen adsorption data. With increasing temperature the pores decrease in size by both nitrogen adsorption and TEM. This is due to a densification process that occurs as the carbon in the foams undergoes rearrangement. At temperatures above $500^{\circ} \mathrm{C}$ the aromatization process is thermally driven by a loss of hydrogen thereby producing new carbon-carbon bonds. As this process occurs there also is a loss in the $\mathrm{sp}^{3}$ character of the system and an increase in the $\mathrm{sp}^{2}$ character.

Acquisition of solid state NMR spectra was less than straightforward. There are three peaks in the spectrum of the starting material: $38 \mathrm{ppm}, 128 \mathrm{ppm}$, and $138 \mathrm{ppm}$. The peak at $38 \mathrm{ppm}$ can be attributed to the bridging methylene unit of the crosslinks. The latter two peaks are due to the aromatic moieties of the foam, the upfield peak being a carbon with an attached proton, and the downfield peak a carbon attached to a bridging carbon. Two notable differences between the spectra of the starting material and the sample pyrolyzed at $500^{\circ} \mathrm{C}$ are the marked decrease in the intensity of peaks at $38 \mathrm{ppm}$ and $138 \mathrm{ppm}$. Since these peaks correspond to carbons attached to hydrogen, this indicates that there is significant dehydrogenation occurring. Spectra obtained at lower temperatures still show a significant amount of hydrogen present in the system through $400^{\circ} \mathrm{C}$. It is between $400^{\circ} \mathrm{C}$ and $500^{\circ} \mathrm{C}$ that this dehydrogenation process occurs. Both the increase of aromaticity and the densification of the foam lead to the increase in conductance of the foam.

The hypercrosslinked biphenyl and its carbonized foams broke the trends observed in the other systems. The distributions for the biphenyl/DCX is atypical for the hypercrosslinked system - a multimodal distribution with a maximum in the microporous regime at $10.4 \AA$ and maximums in the macroporous regime at $290 \AA$ and $700 \AA$. Normally there is only one maximum in the macroporous region circa $700 \AA$ to $1,000 \AA$, depending on the monomers used. As described earlier, the distribution for the vacuum pyrolyzed carBP450 is typical wherein the surface areas are two orders of magnitude lower with a fair retention of the pore size distribution. CarBP450 pyrolyzed in static air was the only low temperature foam to show a decrease in the diameter of the micropores with a retention in surface area of the precursor. The corresponding decrease in the 
meso- and macropore surface area is typically observed during pyrolysis. The shift to larger pore diameters seen for carBP450/1,000 is typical during pyrolysis; however, the retention of surface area is unusual. CarBP1,000 was the only sample to be ramped directly up to $1,000^{\circ} \mathrm{C}$ without the formation of a shiny silver balloon. This sample shrank only slightly and had a dull silver luster. The overall surface area and pore retention was greater than the sample heated to only $450^{\circ} \mathrm{C}$ in vacuum.

Novel Systems. In addition to the systems described above, other novel materials were synthesized. Kraton, a commercially available elastomer, was hypercrosslinked with dichloroxylene to provide a toughened elastomer with improved high temperature properties. In the area of chelating metals, efforts have been made to tether crown ethers to a polymeric support. Such a polymer has been prepared using the technology developed herein.

\section{Conclusions}

Porous polymer foams that are prepared via Friedel-Crafts polycondensation have tailorable properties including a wide range of surface areas (from $160 \mathrm{~m}^{2} / \mathrm{g}$ to greater than $1,200 \mathrm{~m}^{2} / \mathrm{g}$ ). Surface areas are controlled by the pore size distributions in these foams. Properties including density, surface area, pore size, pore size distribution, and thermal stability can be tailored by judicious choice of monomer, crosslinker, catalyst, and cure time. Hypercrosslinked polymers provide a matrix that is amenable to carbonization. Carbonaceous foams can be prepared with a wide variety of surface areas and pore sizes. These properties can be tailored not only by judicious choice of precursor but by pyrolysis conditions as well. Not only are these materials useful for separations, they make good catalyst supports. 


\section{Publications}

Steckle, Jr., W.P.; Mitchell, M.A.; Apen, P.G. "Hypercrosslinked Polymeric Foams by Friedel-Crafts Polycondensation", New Organic Chemistry for Polymer Synthesis Workshop, Div. of Polymer Chem., Amer. Chem. Soc. (1995), Los Alamos National Laboratory document LA-UR-95-1743.

Steckle, Jr., W.P.; Mitchell, M.A.; Apen, P.G. "Tailoring the Pore Size of Hypercrosslinked Polymer Foams", MRS National Meeting (Spring 1966), Los Alamos National Laboratory document LA-UR-95-3487.

Steckle, Jr., W.P.; Mitchell, M.A.; Apen, P.G. "Hypercrosslinked Polymeric Foams by Friedel-Crafts Polycondensation", Polym. Materials Sci. Eng. 74, 344 (1996).

Steckle, Jr., W.P.; Mitchell, M.A.; Apen, P.G. "Tailoring the Pore Size of Hypercrosslinked Polymer Foams" in Microporous and Macroporous Materials, Lobo, R.F., et al., Eds.; MRS Symposium Proceedings Series; Materials Research Society: Pittsbugh, PA; Vol. 431 (1996).

Steckle, Jr., W.P. "Carbon Foams Prepared from Hypercrosslinked Polymer Foams", Polymer Preprints 37(1), 777 (1996).

Steckle, Jr., W.P. "Novel Hypercrosslinked Polymer Systems", Polymer West-Gordon Research Conference (1997), Los Alamos National Laboratory document LA-UR-963573.

Steckle, Jr., W.P. "Carbon Foams Prepared from Hypercrosslinked Polymer Foams", Recent Advances in Polymeric Foam \& Technology, Amer. Chem. Soc. Books, K. Khemani, Ed., Washington, D.C. (1997), Los Alamos National Laboratory document LA-UR-96-3831.

Steckle, Jr., W.P.; Duke, Jr., J.R. "Solid State NMR Studies of Hypercrosslinked Resins", to be submitted to Polymer Preprints. 
References

[1] Ulrich, K.E.; Hawker, C.J.; Frechet, J.M.J.; Turner, S.R. Macromolecules 1992, 25, 4583 and references cited therein.

[2] Kim, Y.H. J.Am Chem.Soc. 1992, 114, 4947.

[3] Kim, Y.H.; Webster, O.W. J.Am.Chem.Soc. 1990, 112, 4592.

[4] Kim, Y.H. (E.I. DuPont de Nemours), US Patent 4,857,630 (1989).

[5] Webster, O.W.; Gentry, F.P.; Farlee, R.D.; Smart, B.E. Makromol.Chem.MacromolSymp. 1992, 54/55, 477.

[6] Shea, K.J.; Loy, D.A.; Webster, O.W. J.Am.Chem.Soc. 1992, 114, 6700.

[7] Davankov, V.A.; Rogoshin, S.V.; Tsyrupa, M.P. J.Polym.Sci.Symp. 1974, 47, 95.

[8] Reed, S.F.; Pinschmidt, R.K. (Rohm and Haas Co.), US Patent 4,191,813 (1980).

[9] Rosenburg, G.I.; Shabaeva, A.S.; Moryakov, V.S.; Musin, T.G.; Tsyrupa, M.P.; Davankov, V.A. React.Polym. 1983, 1,175.

[10] Belyakova, L.D.; Schenchenko, T.I.; Davankov, V.A.; Tsyrupa, M.P. Adv.Coll. Interface Sci. 1986, 25, 249.

[11] Davankov, V.A.; Tsyrupa, M.P. React.Polym. 1990, 13, 27.

[12] Davankov, V.A.; Tsyrupa, M.P. Pure Appl.Chem. 1989, 61(11), 1881.

[13] Davankov, V.A.; Tsyrupa, M.P. Polym.Mater.Sci.\&Eng. 1992, 66, 146.

[14] Overhults, W.C.; Ketley, A.D. Die Makromol.Chem. 1966, 95, 143.

[15] Grassie, N.; Meldrum, I.G. Eur.Polym. J. 1968, 4, 195.

[16] Grassie, N.; Meldrum, I.G. Eur.Polym. J. 1969, 5, 571.

[17] Grassie, N.; Meldrum, I.G. Eur.Polym. J. 1971, 7, 1253.

[18] Hsing, C.-F.; Jones, M.B.; Kovacic, P. J.Polym.Sci.Polym.Chem.Ed. 1981, 19, 973.

[19] Patel, G.R.; Amin, P.T.; Patel, S.R. J.Macromol.Sci.-Chem. 1982, Al8(6), 939.

[20] Patel, G.R.; Patel, S.R. J.Macromol.Sci.-Chem. 1983, A19(5), 653.

[21] Patel, G.R.; Patel, S.R. J.Macromol.Sci.-Chem. 1983, A19(5), 663.

[22] Patel, G.R.; Patel, S.R. J.Macromol.Sci.-Chem. 1983, A19(5), 673.

[23] Nystuen, N.J.; Jones, M.B. J.Polym.Sci.Polym.Chem.Ed. 1985, 23, 1433.

[24] Patel, P.S.; Patel, S.R. J.Macromol.Sci.-Chem. 1986, A23(10), 1251. 
[25] Jones, M.B.; Larson, J.E. J.Polym.Sci.Part A: Polym.Chem. 1992, 30, 2037.

[26] S. Brunauer, P.H. Emmett, and E. Teller, J. Am. Chem. Soc. 60, 309 (1938).

[27] G. Horvath and K. Kawazoe, J. Chem. Eng. Japan 16(6), 470 (1983).

[28] E.P. Barrett, L.S. Joyner, and P.P. Halenda, J. Am. Chem. Soc. 73, 373 (1951).

[29] J.P. Olivier, W.B. Conklin, and M.V. Szombathely, Stud. Surf. Sci. Catal. 87, 81 (1994). 